\title{
Pelvic plastron secondary to acute appendicitis in a child presented as appendiceal intussusception. A case report Efstratios Christianakis ${ }^{1}$, Anastasios Sakelaropoulos ${ }^{2}$, Constantinos Papantzimas ${ }^{3}$, Michael Pitiakoudis ${ }^{4}$, Georgios Filippou ${ }^{5}$, Dimitrios Filippou*5, Spiros Rizos ${ }^{5}$ and Nikolaos Paschalidis ${ }^{5}$
}

\author{
Address: ${ }^{1}$ Dept. of Paediatric Surgery, Pendeli Children's Hospital, Palea Pendeli, Athens, Greece, ${ }^{2}$ Department of Radiology, Pendeli Children's \\ Hospital, Palea Pendeli, Athens, Greece, ${ }^{3}$ First Paediatric Department, Pendeli Children's Hospital, Palea Pendeli, Athens, Greece, ${ }^{4}$ Department of \\ Surgery, Medical School, University of Thrace, Alexandroupoli, Greece and ${ }^{5}$ Department of Anatomy, Nursing Faculty, University of Athens, \\ Athens, Greece \\ Email: Efstratios Christianakis - xristianakis@in.gr; Anastasios Sakelaropoulos - sakelar@yahoo.gr; \\ Constantinos Papantzimas - papatzk@gmail.com; Michael Pitiakoudis - mpitiak@med.duth.gr; \\ Georgios Filippou - georgiosfilippoumd@hotmail.com; Dimitrios Filippou* - d_filippou@ hotmail.com; Spiros Rizos - srizos@otenet.gr; \\ Nikolaos Paschalidis - webdocgr@hotmail.com \\ * Corresponding author
}

Published: I September 2008

Cases Journal 2008, I:135 doi:10.1186/1757-1626-1-135

This article is available from: http://www.casesjournal.com/content/I/I//35

(C) 2008 Christianakis et al; licensee BioMed Central Ltd.

This is an Open Access article distributed under the terms of the Creative Commons Attribution License (http://creativecommons.org/licenses/by/2.0), which permits unrestricted use, distribution, and reproduction in any medium, provided the original work is properly cited.
Received: 19 May 2008

Accepted: I September 2008

\begin{abstract}
We report an unusual case of an I I-year-old Greek girl with complicated acute appendicitis. The pelvic plastron that had been formatted secondary to appendix perforation was mimicking appendiceal intussusception in the preoperative ultrasound and computed tomography images. Although acute complicated appendicitis and appendiceal intussusception may represent possible causes of acute abdomen no similar cases have reported in the literature.
\end{abstract}

\section{Background}

Intussusception of the appendix is a rare type of intussusception with an incidence less than $0.01 \%$ [1]. It is usually mimicking acute or chronic abdominal entities and is usually presented as cecal mass. The diagnosis is difficult to be achieved preoperatively. Appendiceal plastron is not an unusual complication of acute appendicitis in children [2]. Appendiceal plastron presented as intussusception has not been presented previously in the literature.

\section{Case Presentation}

An 11-year-old Greek girl presented in the emergency department complaining for intermittent pain in the lower abdomen, as well as for intermittent fever especially during the nights. The symptoms had been presented 14 days ago. The patient had been examined by a doctor who had administrated in an outpatient basis clarithromycin (tabl. $250 \mathrm{mg}, 1 \times 2$, for 5 days) in combination with amoxycillin plus clavulanic acid (tabl. $500 \mathrm{mg}, 1 \times 3$, for three days) because of the possibility of a streptococcal angina infection. At her admission the patient presented lower abdominal pain, fever $\left(\mathrm{T}=37,5^{\circ} \mathrm{C}\right)$ and brownish colour semi diarrhoeic mucous defecations. For six days the patient was treated conservatively, but she did not improve. On the contrary she remained febrile, with diffuse abdominal pain, tenderness and sensibility in press of the right ilium fossa. From the laboratory and imaging exams X-ray chest, urine and stool cultures were normal, and leucosytosis was the only finding WBC: $18,200 / \mu \mathrm{l}$ (Granulocytes: 80, 3\%). 
The ultrasound of the right lower abdominal quadrant demonstrated in transverse incisions a target lesion with multiple hypoechoid and hyperechoid rings. Longitudinal imagination shows heterogeneous tubular mass, suggesting intussusception of the appendix into the cecum, with a small amount of fluid. There was not clear evidence of the appendix. (Figure 1)

The CT scan with per os administrated contrast suggested cecal intussusception. The main finding was the remaining of the contrast liquid in cecum, the oedema of the cecal wall as well as the misty outline of the mesenteric fat and the lied intestinal loops that suggested peri-appendiceal inflammation. (Figure 2)

The preoperative findings suggested possible appendiceal intussusception and the patient was operated. We used a right sided Pfannenstiel incision. After entering the abdomen an appendiceal pelvic plastron was revealed, while the appendix was not intussuscepted. Because of appendix inflammation, an appendicectomy without burial of the appendix stump was performed. Postoperatively a combination of wide spectrum antibiotics administrated for five days, and the patient discharged at the sixth postoperative day, without presenting any complications.

\section{Discussion}

The most common cause of acute abdomen in children is acute appendicitis (AA), which presents diagnostic problems and followed by severe complications. Non-typical symptoms include diarrhoeas similar to those in acute gastroenteritis. Atypical presentation of a pelvic acute appendicitis complicates the paediatric patients with high frequency $[3,4]$.

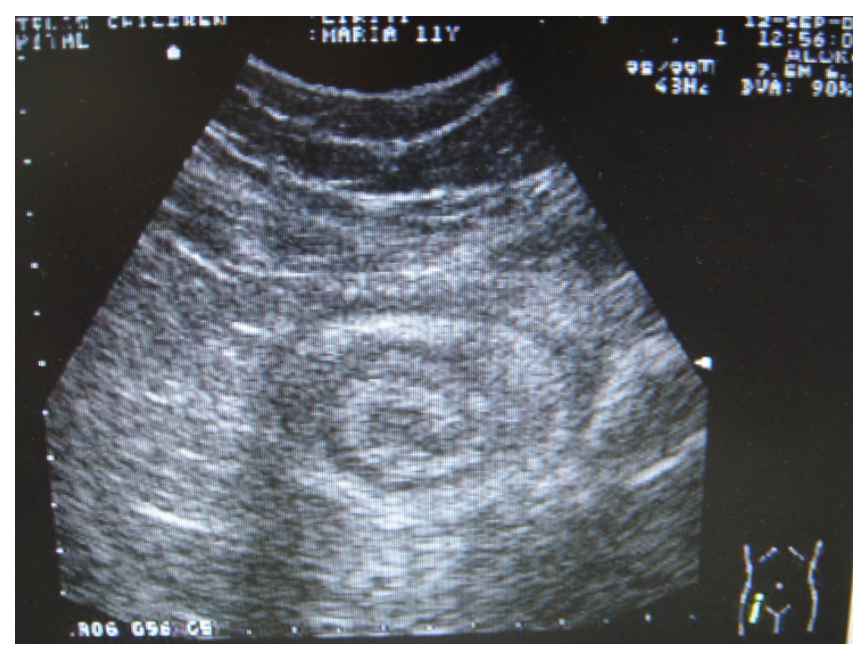

Figure I

US of the lower right abdomen suggesting intussusception of the appendix. A small quantity of fluid can be noticed.

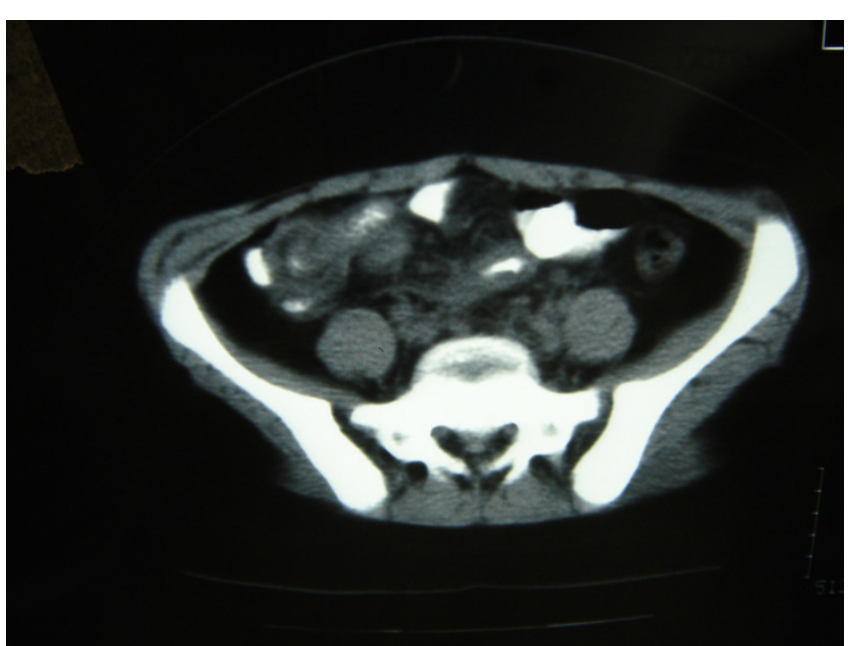

Figure 2

In the CT scan remaining of the contrast liquid in cecum as well as oedema of the cecal wall were observed suggested peri-appendiceal inflammation.

In our case the initial administration of broad spectrum antibiotics may contribute in the delayed diagnosis. The right abdominal lower quadrant pain on palpation, the low-grade fever $\left(38^{\circ} \mathrm{C}\right)$ and the localized tenderness to percussion were the most important clinical signs suggested appendicitis.

Chronic intussusception (CI) is another pathological entity of children that is difficult to diagnose. The CI may last more than 14 days and followed by persistent abdominal pain [4-6]. Non-typical presentation may occur in the non-ischemic type of CI which results in a delayed diagnosis. Generally intussusception presents no such typical picture as the acute type of intussusception, with a long history less severe symptoms, like diarrhoea [7,8]. Also there are infrequent attacks of abdominal pain, sporadic vomiting and no, or small changes in defecation [9-11]. Weight loss and abdominal mass assume diagnostic significance [7]. Approximately 3\% of all reported acute CI cases occur in infants and about $10 \%$ in those over one year of age [11]. The barium enema is usually unsuccessful in hydrostatic reduction and surgery reduction is necessary $[6,7,10,11]$.

\section{Conclusion}

The role of imaging exams (US and CT) in the diagnosis of AA in children may be crucial especially in complicated and obscure cases. In equivocal cases of right lower quadrant pain, these exams may contribute to an earlier diagnosis of AA reducing the rate of unnecessary appendicectomies $[12,13]$. However, risk groups of children who would benefit most from imaging studies have not been established [14]. 


\section{Abbreviations}

mg: milligrams; $\mathrm{T}$ : temperature; ${ }^{\circ} \mathrm{C}$ : Celcious degrees; WBC: white blood cells; CT: computed tomography; AA: acute appendicitis; CI: chronic intussusception; US: ultrasound

\section{Competing interests}

The authors declare that they have no competing interests.

\section{Authors' contributions}

All authors (EC, AS, CP, MP, GF, DF, SR, NP) contributed equally to the patient's therapy, writing the present case report and approving it.

\section{Consent section}

Written informed consent was obtained from the patient for publication of this case report and accompanying images. A copy of the written consent is available for review by the Editor-in-Chief of this journal.

\section{References}

I. Collins DC: Seventy-one thousand human appendix specimens: a final report summarizing 40-year study. Am J Proctol 1963, | 4:365-8I.

2. Hardin DM: Acute appendicitis: Review and Update. American Family Physician 1999, 60:2027-2034.

3. Murch SH: Diarrhoea, diagnostic delay and appendicitis. The Lancet 2000, 356:787.

4. Chang ML, Cheung W, Ling YK, Chiu WW: Chronic intussusception in children: report of one case. Zhonghua Min Guo Xiao Er Ke Yi Xue Hui Za Zhi 1994, 35:335-40.

5. Reijnen JA, Festen C, Joosten HJ: Chronic intussusception in children. BrJ Surg 1989, 76:815-6.

6. West NJ, Daniels IR, Carr ND: Chronic intussusception in children. J Royal Soc Prom Health 2003, I 23: I8I-4.

7. Schulman H, L Laufer, Kurzbert E, Cohen Z, Hertzanu Y: Chronic intussusception in children. Eur Radiol 8: |455-|456.

8. Shekhawat NS, Prabhakar G, Sinha DD, Goyal RB, Gupta A, Sharma RK, Sogani KC: Nonischemic intussusception in childhood. J Pediatr Surg 1992, 27:|433-5.

9. Henry A, Reisman A, Wolk AD: Chronic intussusception. Pediatrics 1949:183-7.

10. Rees BI, Lari J: Chronic intussusception in children. $B r$ J Surg 1976, 63:33-5.

II. Jaward AJ, Sibli SY, Sahni PS, Malabarey T: Chronic intussusception. An Saudi Med 1997, I 7:545-7.

12. Even-Bendahan G, Lazar I, Erez I, Guttermacher M, Verner M, Konen $\mathrm{O}$, Rathaus $\mathrm{V}$, Freud $\mathrm{E}$ : Role of imaging in the diagnosis of acute appendicitis in children. Clin Pediatr (Phila) 2003, 42:23-7.

13. Kosloske AM, Lance Love C, Rohner JE, Goldthorn JF, Lacey SR: The diagnosis of appendicitis in children: Outcomes of a strategy based on pediatric surgical evaluation. Pediatr 2004, I I 3:29-34.

14. Garcia Pena BM, Cook EF, MadI KD: Selective imaging strategies for the diagnosis of appendicitis in children. Pediatr 2004, I | 3:24-28.

\section{Publish with Bio Med Central and every scientist can read your work free of charge}

"BioMed Central will be the most significant development for disseminating the results of biomedical research in our lifetime. "

Sir Paul Nurse, Cancer Research UK

Your research papers will be:

- available free of charge to the entire biomedical community

- peer reviewed and published immediately upon acceptance

- cited in PubMed and archived on PubMed Central

- yours - you keep the copyright
BioMedcentral 